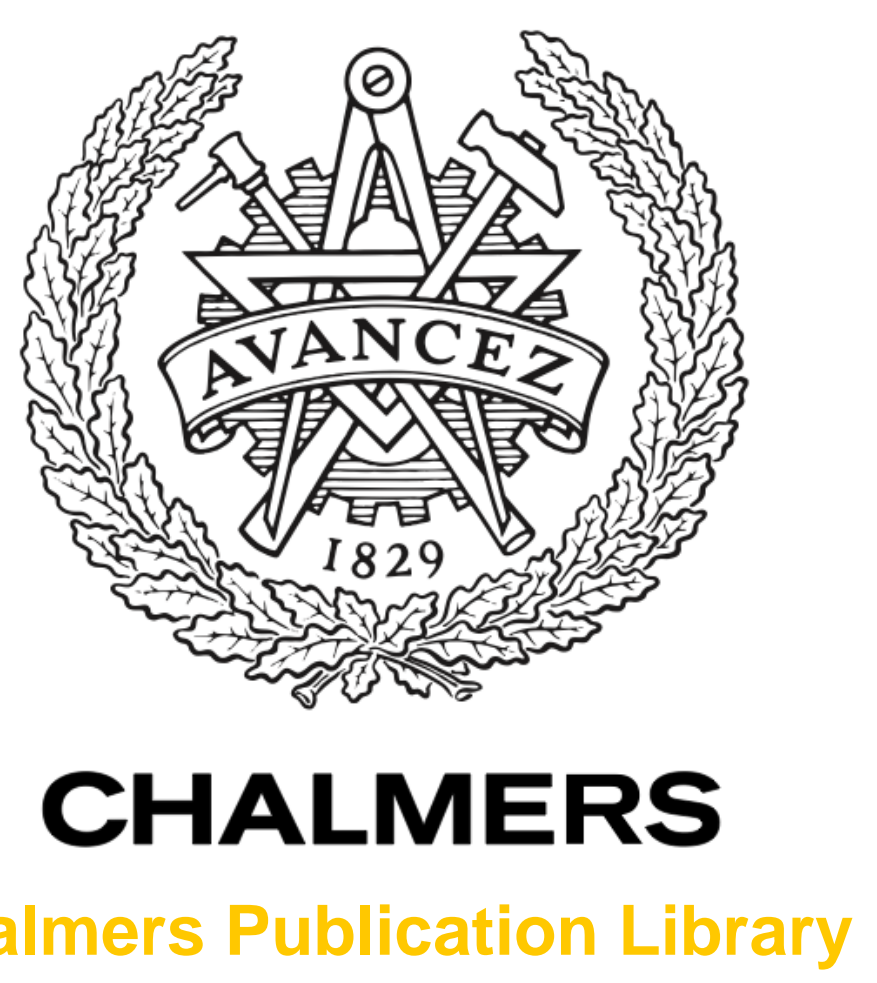

Challmers Publication Library

A multi-level structural assessment strategy for analysis of RC bridge deck slabs

This document has been downloaded from Chalmers Publication Library (CPL). It is the author's version of a work that was accepted for publication in:

19th IABSE Congress Stockholm (pp. 1559-1566). Stockholm, Sweden

Citation for the published paper:

Plos, M. ; Shu, J. ; Lundgren, K. (2016) "A multi-level structural assessment strategy for analysis of RC bridge deck slabs". 19th IABSE Congress Stockholm (pp. 1559-1566).

Stockholm, Sweden pp. 1564-1571.

Downloaded from: http://publications.lib.chalmers.se/publication/248020

Notice: Changes introduced as a result of publishing processes such as copy-editing and formatting may not be reflected in this document. For a definitive version of this work, please refer to the published source. Please note that access to the published version might require a subscription.

Chalmers Publication Library (CPL) offers the possibility of retrieving research publications produced at Chalmers University of Technology. It covers all types of publications: articles, dissertations, licentiate theses, masters theses, conference papers, reports etc. Since 2006 it is the official tool for Chalmers official publication statistics. To ensure that Chalmers research results are disseminated as widely as possible, an Open Access Policy has been adopted.

The CPL service is administrated and maintained by Chalmers Library. 


\title{
A multi-level structural assessment strategy for analysis of RC bridge deck slabs
}

\author{
Mario Plos, Jiangpeng Shu, Karin Lundgren \\ Chalmers University of Technology, Göteborg, Sweden
}

\author{
Kamyab Zandi \\ CBI Swedish Cement and Concrete Research Institute, Borås, Sweden
}

Contact: mario.plos@chalmers.se

\begin{abstract}
A multi-level structural assessment strategy for evaluation of response and load carrying capacity of reinforced concrete bridges deck slabs are presented [1]. The strategy is based on the principle of successively improved analysis methods in structural assessment. It provides a structured approach to the use of simplified as well as advanced non-linear finite element analysis methods. The proposed methods were used for analysis of previously tested slabs subjected to bending and shear type of failures. As expected, the advanced methods gave an improved understanding of the structural response and were capable of demonstrating higher, yet conservative, predictions of the load-carrying capacity. The proposed strategy clearly provides the engineering community a framework for using successively improved structural analysis methods for enhanced assessment in a straightforward manner.
\end{abstract}

Keywords: Multi-level assessment; reinforced concrete slabs; non-linear finite-element analysis; load-carrying capacity; bending failure; shear-type failure.

\section{Introduction}

It is of high importance to have accurate methods for assessment of load-carrying capacity and mechanical response for bridges, buildings and other structures. The existing infrastructure and built environment represent approximately 50\% of the national wealth in most European countries, and the maintenance and repair of these structures constitute around $50 \%$ of the expenditure in the construction industry, Long et al. [2]. Furthermore, there is an increased demand for greater load-carrying capacities and reassessment of transport infrastructure. For bridges, the bridge deck slabs are among the most exposed parts and are often critical for the loadcarrying capacity.

In the assessment of existing structures, it is often economic to use more accurate and detailed calculation models to better detect the real loadcarrying capacities, than what is motivated in the design of new structures, [3]. With non-linear finite element (FE) analysis, the structural response for a given set of actions can be simulated realistically. For reinforced concrete (RC) structures, the influence of concrete cracking and crushing, reinforcement yielding and the 


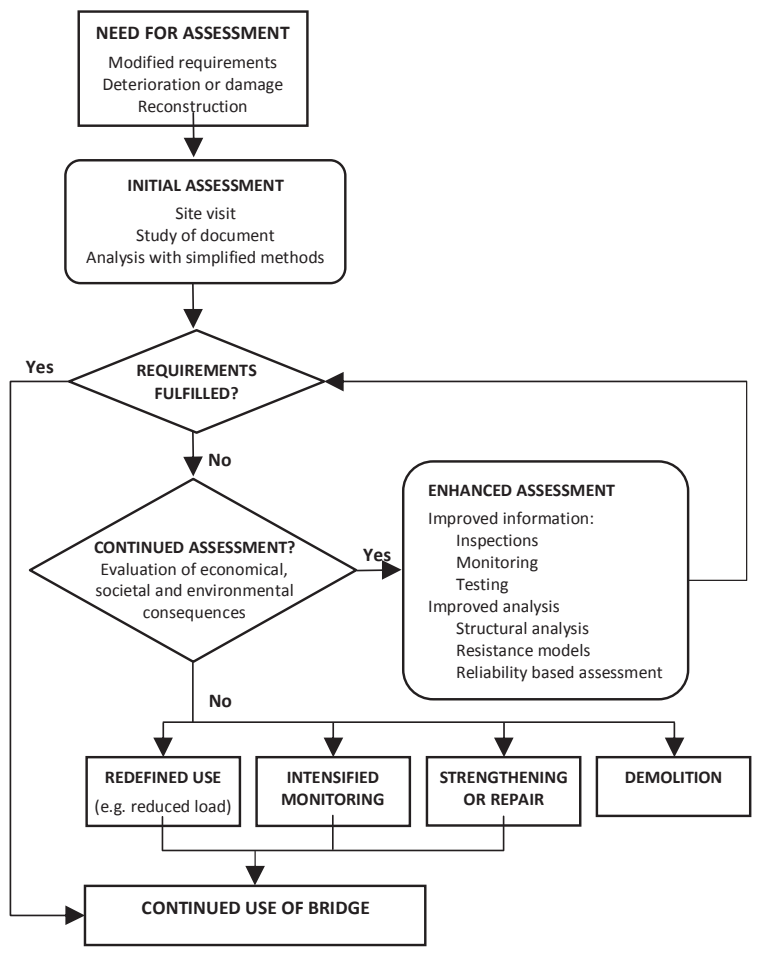

Figure 1. Flow diagram for structural assessment based on the principle of successively improved evaluation.

bond-slip interaction between concrete and reinforcement can be included. It has been stated that "non-linear FE analysis has the highest potential from all the analysis method for discovering any additional sources for loadcarrying capacity" [4] in the assessment of RC bridges. With such methods, higher detectable load-carrying capacity will in turn lead to lower life cycle costs and reduced environmental impact.

For structural assessment of existing bridges a step-level procedure is advantageous, where successively improved evaluation methods are used as an integrated part of the decision process [3]. As illustrated in Figure 1, the assessment normally starts with calculations using simplified design methods based on existing documentation and inspection protocols. If safety cannot be assured, or if inspections reveal damage to the structure, enhanced assessment can be performed. This can include improved information through inspections, monitoring and testing, or deeper studies of the documentation. More advanced structural analysis and resistance models that are more accurate and reliable can also be used.

However, even though the principle of successively improved evaluation for structural assessment is a sound strategy, it has only been described in general terms in the literature. When used in engineering practice, it is left to bridge engineers to decide upon the most suitable method for each individual case. Consequently, there is a need for more detailed recommendations regarding suitable analysis methods at different assessment levels for each specific type of structure.

The aim was therefore to propose an assessment strategy for the structural assessment of RC bridge deck slabs and to demonstrate and examine the strategy in case studies [1]. The assessment strategy comprises structural analysis at five levels of detail and accuracy, ranging from simplified methods of the current dominate design methods to enhanced non-linear FE analysis. The proposed method was demonstrated and validated in two case studies, representing different slab geometries and failure modes relevant to engineering practice.

\section{A Multi-Level Structural Assess- ment Strategy}

The multi-level assessment strategy for RC bridge deck slabs is based on the principle of successively improved evaluation in structural assessment [3], illustrated in Figure 1. It focuses on enhanced assessment through improved structural analyses and resistance evaluations. For RC bridge deck slabs, different assessment levels according to Figure 2 may be distinguished. Evaluation of the structural response and load-carrying capacity can be made with structural analysis at levels ranging from simplified methods (I) over the currently dominant design methods based on linear $\mathrm{FE}$ analysis (II) to non-linear FE analysis at different levels of detailing (III-V). If the failure mode in question is not reflected in the analysis, the structural analysis needs to be combined with local resistance models. It is desirable that the models for structural analysis and for the determination of local resistance are, as far as 


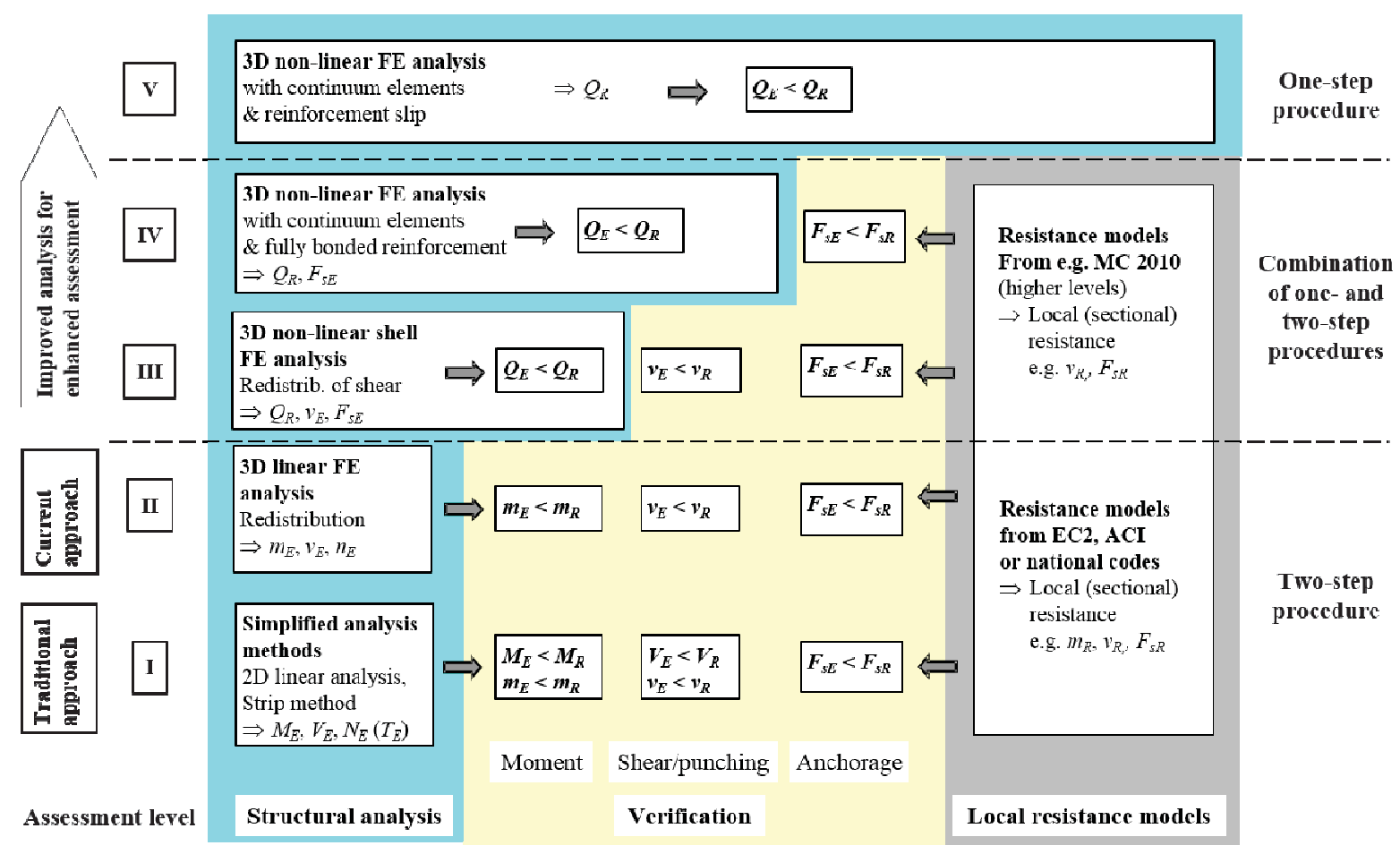

Figure 2. Scheme for multi-level assessment of reinforced concrete bridge decks

possible, at equivalent levels of accuracy. In the assessment process, Figure 1, it is reasonable to use analysis on level I or II for the initial assessment. If the assessment is continued with enhanced methods, improved structural analysis and resistance models on higher assessment levels (II to V) can be utilized successively within to the "loop" for continued assessment indicated in the figure.

The proposed assessment levels are briefly described below, and are exemplified by two case studies in Sections 3.

\subsection{Level I: Simplified analysis methods}

At this level, the structural system is commonly simplified to 2D beam or frame models with a preassumed load distribution along the main directions. For a RC slab, this can be generalised as the strip method [5]. In both cases, the structural model is based on the lower bound theorem of plasticity. The analysis can be complemented by the yield line method [6], giving an upper bound for the plastic load-carrying capacity. The limited plastic deformation capacity of the slab can be accounted for by limitations of the load distribution widths, e.g., BBK 04 [7]. For two-way spanning slabs, there are also solutions tabulated in handbooks for the distribution of load effects.

The load effects are compared with corresponding resistances determined by local models for bending, shear, punching and anchorage of reinforcement. Common design resistance models are used, as described in e.g., the Eurocode 2 [8], $\mathrm{ACl}$ 318-05 [9] or national regulations.

\subsection{Level II: 3D linear shell FE analysis}

Here, the structural analysis is performed using 3D FE models, most often based on shell or bending plate theory. The analysis is performed assuming linear response to be able to superimpose the effect of different loads, in order to achieve the maximum load effects in terms of cross-sectional forces and moments throughout the structure for all possible load combinations. Since both the assumption of linear material response and geometrical simplifications result in unrealistic stress concentrations, and because the reinforcement is often arranged in strips with 
equal bar diameter and spacing, redistribution of the linear cross-sectional forces and moments are necessary. Recommendations on redistribution widths for bending moments and shear forces are given in Pacoste et al. [10]. The load effects are compared with corresponding resistances in similar way as at level I.

\subsection{Level III: 3D non-linear shell FE analysis}

In a non-linear analysis, the loads are successively increased until failure of the structure is reached. In practice, due to the excessive amount of work it would require, non-linear analysis cannot be performed for all possible load combinations, but only for the most critical loads determined previously in the assessment process. At this assessment level, shell (or bending plate) finite elements are used. The reinforcement is included in the FE model but assumed to have perfect bond to the concrete; it is preferably modelled as embedded reinforcement [11] layers in the shell elements, strengthening the concrete in the direction and at the level of the reinforcement bars. In such a model, bending failures will be reflected in the analysis, whereas out-of-plane shear, punching, or anchorage failures are not reflected. Instead they must be checked by local resistance models. With this level of accuracy on the structural analysis, resistance models at higher levels of approximation according to MC2010 [12] are preferably used. For shear type failures, models taking into account the in-plane stressstate from the non-linear analysis are recommended.

\subsection{Level IV: 3D non-linear FE analysis with continuum elements and fully bonded reinforcement}

Here, the non-linear analysis is performed using 3D continuum elements representing the concrete. Similarly to level III, the reinforcement is assumed to have perfect bond and no slip to the concrete [11]; embedded reinforcement layers can be used in coarse FE meshes, while individual (embedded) bars may be preferred in dense meshes with elements smaller than the reinforcement bar distances, to better reflect the crack pattern. In such an analysis both bending and shear type failures including punching can be reflected. However, anchorage failures need to be checked with the help of separate resistance models.

\subsection{Level V: 3D non-linear FE analysis with continuum elements including reinforcement slip}

Compared to level IV analysis, the reinforcement is modelled using separate finite elements. Furthermore, the bond-slip behaviour of the interface between the reinforcement and the concrete is included. With a fine mesh, individual cracks can be studied and anchorage failure can be reflected in the analysis. With this level of accuracy in the structural analysis, the intention is that no major failure modes should be necessary to check using separate resistance models.

\subsection{Safety format}

For each level of assessment, a relevant safety format should be used. When a two-step procedure is used to determine the load-carrying capacity, as at levels I and II, the partial factor method is normally used. For non-linear analysis, using a one-step procedure to determine the loadcarrying capacity at the structural level, safety formats based on global safety factors according to MC2010 [12] are recommended. This applies to level V as well as levels III and IV for the types of failures reflected in the non-linear analysis. When failure modes not reflected in the analysis are checked via separate resistance models, the partial factor method is an appropriate choice. This means that separate structural analyses may be needed to check different failure modes for level III and IV.

When safety formats based on global safety factors are used, and bending failures in skew directions and shear type failures govern the capacity, the modelling uncertainty used should be given special attention since the values given in MC2010 [12] might be too low, see Schlune et al. [13].

\subsection{Deterioration and buckling}

When the structure is deteriorated due to causes such as reinforcement corrosion, frost damage or 
alkali-silica reaction, the structural effect of the deterioration needs to be accounted for in the analysis. At levels I and II, the deterioration will affect the structural analysis only if the stiffness relations are altered, whereas the resistance calculations are more directly influenced. With non-linear structural analysis at levels III - V, lowered material strength, concrete cover spalling and deteriorated reinforcement-concrete interaction may directly be included in the analysis. Recommendations on how to take into account the effect of deterioration can be found in Zandi Hanjari et al. [14,15] for reinforcement corrosion and in Zandi Hanjari et al. [16,17] for frost damage.

When global buckling might be critical, this can be taken into account in analyses at levels III $-\mathrm{V}$ by including geometric non-linearity and initial imperfections in the FE analysis. The level of assessment that is needed in each individual case is governed by the local failure mode limiting the deformations. For most cases, when bending is limiting the deformations, analysis at level III will be sufficient.

\subsection{General considerations}

Even though assessment at more enhanced levels provide improved understanding and higher detectable load carrying capacity, the increased cost in terms of additional working hours and computation time must be weighted in relation to what can be gained before choosing whether to proceed with analyses at higher levels. The benefit of performing more advanced structural analysis must also be weighed against other methods to improve the assessment, e.g., improved inspections, monitoring and testing and reliability-based assessment.

When evaluating simple structures it might not be likely to gain much by improved structural analysis beyond a certain level. For example, for a simple structure like a simply supported one-way spanning slab with distributed load, it is not likely to gain much by going beyond level I or II; for a two-way spanning slab failing due to bending, it is probably not possible to show much higher loadcarrying capacity when going beyond level III.

\section{Application in two case-studies}

The proposed method was demonstrated and validated in two case studies, representing different slab geometries and failure modes relevant to engineering practice. The case studies consisted of (a) two-way slabs subjected to bending failure [18], and (b) a cantilever slab subjected to a combination of shear and punching failure [19], see Figure 3. Both types of slabs have been tested under concentrated loads. The capability of the different proposed assessment levels to reflect the structural response and predict the load-carrying capacity of the slabs studied was evaluated by comparison to the test results.
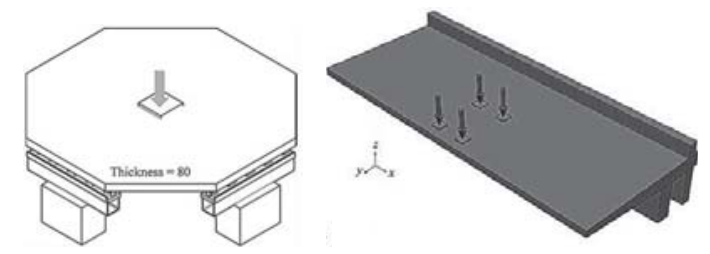

Figure 3. Experiments used for the case study: twoway slabs subjected to bending failure [18] (left), and a cantilever slab subjected to a combination of shear and punching failure [19] (right).

The predicted load-carrying capacities were calculated using mean values of material parameters at all different levels. In this way, the different safety formats or chosen safety levels did not influence the comparison. Instead, it was the capability of the structural analysis and resistance models to predict the load-carrying capacities that was evaluated and compared to test results. A thorough description of modelling methods are found in [1].

For analysis at Level I: Simplified analysis methods, the load-carrying capacity with respect to bending failure was estimated using the strip method [5] and the yield line method [6]. The resistance was checked according to Eurocode 2 [8] for bending, one-way shear, punching and anchorage.

For analysis at Level II: 3D linear shell FE analysis, the slab was modelled with eight-noded rectangular shell elements. Distribution widths and reinforcement moments for load effect calculations were determined according to [10]. 
Resistances were calculated according to Eurocode 2 [8].

For analysis at Level III: non-linear 3D linear shell FE analysis, a similar FE model as for Level II was used, but with non-linear material and geometry effects included. A fracture energy based total strain rotating crack model [20] was used for the concrete, with an isotropic damage constitutive law for the compressive response. The reinforcement was included as fully bonded embedded reinforcement. The analysis was carried out using displacement control. The resistance for shear and punching was checked separately based on MC2010 [12]. The punching capacity was calculated using the slab rotations from the non-linear FE analysis by applying the critical shear crack theory by Muttoni [21] according to MC2010.

For analysis at Level IV: 3D non-linear FE analysis with continuum elements and fully bonded reinforcement, the slab was modelled with 8noded brick elements. For the two-way slab eight first order elements were used over the slab thickness, while second order elements with three elements over the slab thickness were used for the cantilever slab to limit the model size and thereby the computational time. The same material models and fully bonded embedded reinforcement as at Level III was used. At this level of analysis, all critical failure modes were reflected in the analysis and only anchorage failure was checked by a separate resistance model [8].

The models at Level V: 3D non-linear FE analysis with continuum elements including reinforcement slip, were identical to the Level IVmodels, except for the modelling of reinforcement. Here, separate elements were used for the reinforcement bars and a bond-slip behaviour according to MC1990 [22] was included to better describe the interaction between reinforcement and concrete. No separate resistance checks were made.

\section{Results}

The load-carrying capacity at level I-II and the load-deflection responses from non-linear FE analyses at level III-V and from the tests are displayed in Figure 4 for the two cases.
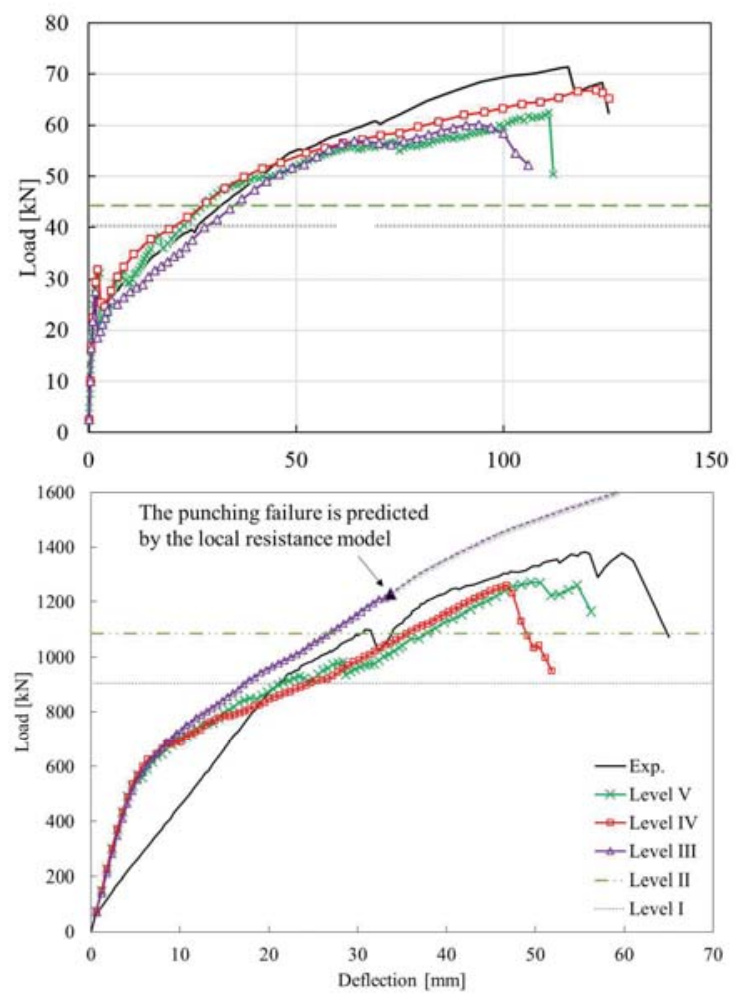

Figure 4. Load-deflection response and loadcarrying capacity the case study slabs: two-way slabs (above), and cantilever slab (below).

In Figure 5, the crack pattern from the analyses on levels III-V are compared to the tests. It is evident that the load-deflection behaviour as well as the flexural cracking in the non-linear analyses well reflects the experiments with increased accuracy and level of detail with higher level of detailing in the modelling. Also the successive development of reinforcement yielding is reflected. For analyses on level IV-V the shear cracks and shear type failure in the cantilever slab are also well reflected, Figure 14. In figure 15 and 16, the detectable load carrying capacity with analysis at different levels are compared with experimental results. It is obvious that the detectable loadcarrying capacity generally was higher for higher levels of assessment, but was always lower than the experimental value.

\section{Conclusions}

A novel multi-level assessment strategy for reinforced concrete bridge deck slabs has been proposed [1]. The strategy is based on the 


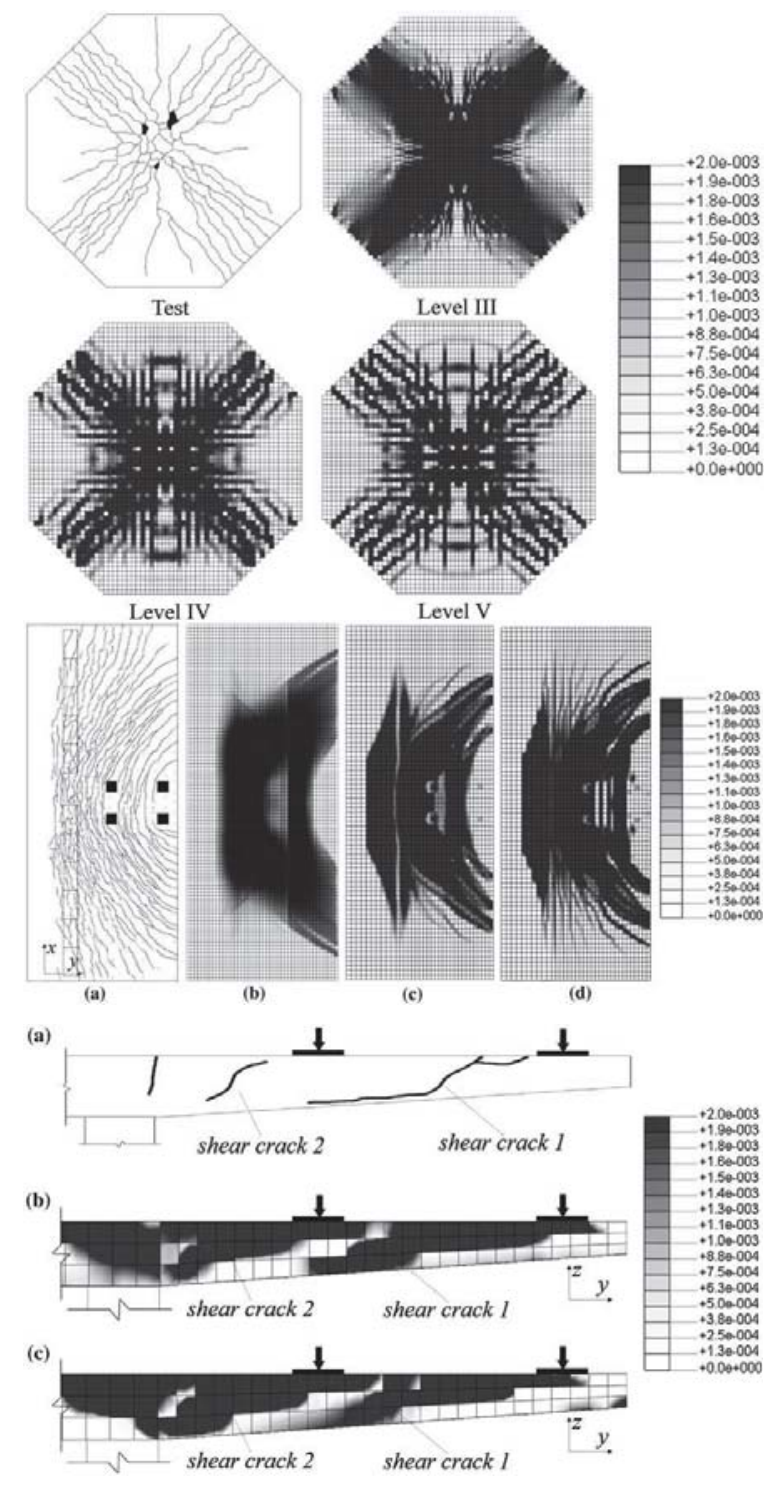

Figure 5. Crack pattern from experiment and the strain-based crack pattern from FE analysis on levels III-V at the top surface of the two-way slabs (above) and cantilever slab (middle), and atr the symmetry cross-section of the cantilever slab for level IV-V (below) at 95\% of the ultimate load ( $\varepsilon=2 e-3$ indicates fully open cracks).

principle of successively improved evaluation in structural assessment. It provides the engineering community a framework for using successively improved structural analysis methods for enhanced assessment in a straight forward manner. The proposed strategy was evaluated on two case studies, including slabs subjected to bending and shear type failures, that shows that

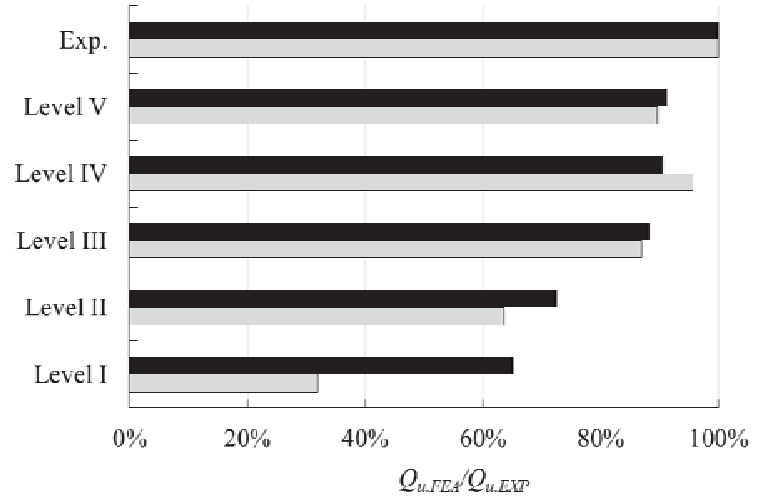

Figure 5. Load-carrying capacity determined by assessment on level I- $V$, in relation to experimental results: for the two-way slab subjected to bending failure (grey), and the cantilever slab subjected to combined shear and punching failure (black).

the proposed assessment strategy and analysis methods are valid and give conservative estimates of the load carrying capacity. Even though it was demonstrated on simple structures tested in laboratory only, the strategy is intended and suited for assessment of real full-scale structures like bridge deck slabs in engineering practice. As expected, the case studies show that more advanced methods yield an improved understanding of the structural response and are capable of demonstrating higher, yet conservative, predictions of the load-carrying capacity.

Furthermore, the presented case studies demonstrate that non-linear FE analysis (levels III, IV and V) gives improved understanding of the structural response for $\mathrm{RC}$ slabs because e.g. the load-deflection response and crack pattern are obtained from the analysis, and it is possible to witness where and how the slab failed. The case studies indicate that the largest improvement in detectable load carrying capacity can be obtained when using non-linear shell FE analysis (level III) instead of linear analysis (level II). This was observed not only for bending failure, but also for shear type failure when combined with more advanced resistance models according to MC2010 [12]. However this needs to be verified through more case studies.

The authors would like to gratefully acknowledge the support and funding from Swedish Transport 
Administration (Trafikverket), which made the research possible.

\section{References}

[1] Plos M., Shu J., Zandi K., and Lundgren K. A multi-level structural assessment strategy for reinforced concrete bridge deck slabs. Accepted for publication in Structure and Infrastructure Engineering. 2016.

[2] Long, A. E., Henderson, G. D., \& Montgomery, F. R. (2001). Why assess the properties of near-surface concrete? Construction and Building Materials, 15(2-3), 65-79.

[3] SB-LRA. (2007). Guideline for Load and Resistance Assessment of Existing European Railway Bridges. Sustainable Bridges: Report.

[4] SB-4.5. (2007). Non-Linear Analysis and Remaining Fatigue Life of Reinforced Concrete Bridges. Sustainable Bridges: Report.

[5] Hillerborg, A. (1996). Strip method design handbook. London: Technology \& Engineering.

[6] Johansen, K. W. (1972). Yield-Line formulae for slabs. (ISBN 0-721.). London: Cement and Concrete Association.

[7] Boverket. (2004). Boverkets handbok om betongkonstruktioner. Vällingby: ISBN 917147-816-7.

[8] EN 1992-1-1. (2004). Eurocode 2: Design of concrete structures - part 1-1: General rules and rules for buildings. Brussels, Belgium: CEN European Committee for Standardization.

[9] ACl Committee 318. (2011). Building Code Requirements for Structural Concrete and Commentary. Farmington Hills, Mich: $\mathrm{ACl}$ American Concrete Institute.

[10] Pacoste, C., Plos, M., \& Johansson, M. (2012). Recommendations for finite elemetn analysis for the design of reinforced concrete slabs. Stockholm: TRITA-BKN Rapport 114.
[11] Schreppers, G. (2011). Embedded Reinforcements. Delft: Technical report, TNO DIANA BV

[12] CEB-FIP. (2013). fib Model Code for Concrete Structures 2010. Lausanne.

[13] Schlune, H., Plos, M., \& Gylltoft, K. (2011). Safety formats for nonlinear analysis tested on concrete beams subjected to shear forces and bending moments. Engineering Structures, 33(8), 2350-2356.

[14] Zandi Hanjari, K., Kettil, P., \& Lundgren, K. (2011). Analysis of mechanical behavior of corroded reinforced concrete structures. ACl Structural Journal, 108(108), 532-541.

[15] Zandi Hanjari, K., Lundgren, K., \& Coronelli, D. (2011). Bond capacity of severely corroded bars with corroded stirrups. Magazine of Concrete Research, 63(12), 953-968.

[16] Zandi Hanjari, K., Utgenannt, P., \& Lundgren, K. (2011). Experimental study of the material and bond properties of frostdamaged concrete. Cement and Concrete Research, 41(3), 244-254.

[17] Zandi Hanjari, K., Kettil, P., \& Lundgren, K. (2013). Modeling the Structural Behavior of Frost-damaged Reinforced Concrete Structures. Structure and Infrastructure Engineering, 9(5), 416-431.

[18] Fall, D., Shu, J., Rempling, R., Lundgren, K., \& Zandi, K. (2014). Two-way slabs: Experimental investigation of load redistributions in steel fibre reinforced concrete. Engineering Structures, 80, 61-74.

[19] Vaz Rodrigues, R., Fernández Ruiz, M., \& Muttoni, A. (2008). Shear strength of R/C bridge cantilever slabs. Engineering Structures, 30(11), 3024-3033.

[20] TNO. (2012). Diana finite element analysis, User's Manual -- Release 9.4.4. TNO DIANA BV. Delft.

[21] Muttoni, A. (2009). Punching Shear Strength of Reinforced Concrete Slabs. ACI Structural Journal, (105), 440-450.

[22] CEB-FIP. (1993). CEB-fib Model Code for Concrete Structures 1990. Lausanne. 